\title{
Prevalence and risk factors for udder cleft dermatitis in dairy cattle
}

\author{
K. Persson Waller, ${ }^{*} \dagger^{1}$ M. Bengtsson, $\dagger$ and A.-K. Nyman* \\ *Department of Animal Health and Antimicrobial Strategies, National Veterinary Institute (SVA), SE-75189 Uppsala, Sweden \\ †Department of Clinical Sciences, Swedish University of Agricultural Sciences, SE-75007 Uppsala, Sweden
}

\section{ABSTRACT}

Udder cleft dermatitis (UCD) is a skin lesion in dairy cattle mostly located at the anterior junction between the udder and the abdominal wall or between the front quarters. Relatively little is known about causative factors for UCD, and few studies have investigated prevalence and risk factors of UCD. Therefore, the aim of this study was to investigate the prevalence of UCD in a random sample of dairy herds with freestalls and milking parlors in a county of Sweden. Thirty dairy herds participated in the study. Each herd was visited once at milking, when every third cow was investigated for presence of UCD. Associations between UCD and milk production, breed, parity, days in milk, claw health, and udder health on the herd and cow levels were also investigated. In addition, a case-control study was performed in 6 herds with a high prevalence of UCD to investigate associations between udder conformation or mange and UCD. Udder cleft dermatitis was found in $18.4 \%$ of the 1,084 cows included in the study. The within-herd cow prevalence varied between zero and $39 \%$, with an average of $18.5 \%$. Risk factors for UCD at the herd level were a high proportion of Swedish Red cows and a high production level. At the cow level, breed, parity, and production level were identified as risk factors. The highest risk of having UCD was found in high-producing Swedish Red cows that had calved at least 3 times. Veterinary-treated clinical mastitis was associated with UCD, but cow composite somatic cell count was not. A strong anterior udder attachment was a protective factor, but signs of mange had no association with UCD. The primary cause of UCD is still unclear, and more research is needed to identify the best ways to prevent the development of this animal welfare problem.

Key words: dairy cow, udder cleft dermatitis, mastitis, risk factor

Received June 26, 2013.

Accepted October 2, 2013.

${ }^{1}$ Corresponding author: karin.persson-waller@sva.se

\section{INTRODUCTION}

Udder cleft dermatitis (UCD) is a skin lesion located at the anterior junction between the udder and the abdominal wall or between the front quarters of the udder (Beattie and Taylor, 2000; Warnick et al., 2002; Hansen and Nissen, 2010). The lesions vary in appearance and size, but thickened skin, crusts, pus, and wounds that easily bleed are common findings. Udder cleft dermatitis can be difficult to detect due to its anatomical position and the fact that affected cows seldom show general signs of disease.

Few studies on UCD prevalence have been published, and most have included only one or a few herds, mainly categorized as problem herds (Beattie and Taylor, 2000; Warnick et al., 2002; Evans et al., 2010; Hansen and Nissen, 2010). The within-herd prevalence in those studies varied between 0 and $22 \%$. In a recent Dutch study, however, 20 herds were included, of which 3 had no UCD, whereas the within-herd prevalence in the other herds varied between 2.5 and 13\% (Amersfort et al., 2012).

The etiology of UCD is unclear, but several factors, such as udder conformation (Beattie and Taylor, 2000; Hansen and Nissen, 2010, Amersfort et al., 2012), udder edema (Beattie and Taylor, 2000), and mange (Allenstein, 1991, Warnick et al., 2002), have been suggested to play a role. Cow factors such as parity and DIM have also been associated with UCD (Beattie and Taylor, 2000; Warnick et al., 2002; Hansen and Nissen, 2010). An association between UCD and mastitis has been suggested, but this was not supported by Warnick et al. (2002). Moreover, a link between UCD and digital dermatitis was suggested in some studies (Boyer and Singleton, 1998; Stamm et al., 2009), whereas other studies have shown a weak link (Beattie and Taylor, 2000), no link (Hansen and Nissen, 2010), or a lower risk for UCD (Warnick et al., 2002) in cows with digital dermatitis compared with cows without digital dermatitis.

Cases of UCD have also been observed in Swedish dairy cows (Persson Waller, 2003), but the prevalence of the disease is unknown. Thus, the aim of this study was to investigate the prevalence of UCD in a random sample of freestall dairy herds within a region of Sweden, and to identify important risk factors for UCD. 


\section{MATERIALS AND METHODS}

Two studies were performed. In the first study, the prevalence of UCD and associations between presence of UCD and several herd- and cow-level risk factors were evaluated in 30 herds in the county of Östergötland, Sweden. The second study was a case-control study in 6 herds with a high prevalence of UCD in the first study. Both studies were performed from September to November 2012. All herd visits were conducted by the second author.

\section{Prevalence and Risk Factors in Dairy Herds}

For practical reasons, only herds in the county of Östergötland were included in the studies. Other herd inclusion criteria were affiliation with the official milk recording scheme, freestall housing, herd size of 50 to 500 cows, and milking parlor. The latter criterion was chosen to facilitate investigation of the udders at milking. According to data from the Swedish Dairy Association, 40 dairy herds fit the criteria. A letter with information about the project was send to those herds in August 2012, and they were contacted via telephone. Eleven farms were omitted, 3 because of introduction of automatic milking system, 1 had ceased to produce milk, and 7 declined to participate in the study. One herd, wrongly reported to have a tiestall system, was later included in the study, resulting in a total of 30 herds participating in the study.

Each herd was visited once in connection with milking, and every third cow entering the milking parlor was inspected visually for signs of UCD using a hand-held mirror. The skin of the anterior junction between the udder and the abdominal wall and between the front quarters of the udder was also palpated. New disposable gloves were used when investigating each cow. Depending on the findings, cows were classified as having no UCD (no visual or palpable skin damages), mild UCD (hyperkeratosis, small papulae/pustulae, small crusts, or serum transudation), or severe UCD (pus, deep skin wounds, or proliferations with or without findings of mild UCD).

Herd and Cow Data. Herd and cow data on monthly milk recordings (daily milk production, cow composite milk SCC), registrations of veterinary-treated cases of diseases, and claw trimming were collected from the official milk recording scheme and from the animal disease recording system for the period May 2012 to October 2012. Information on breed, parity, calving dates, genetic merit, and culling, when applicable, was also collected from the same source. At the herd visits, a questionnaire was used to collect informa- tion on farmer awareness of UCD, treatments of UCD, and type of bedding material used for lactating cows.

Statistics. In each herd, the UCD prevalence among lactating cows was calculated. The mean prevalence for all herds was also calculated. Associations between the dependent variable, number of UCD cases per herd, and the independent variables (herd factors) were investigated using univariable and multivariable Poisson regression models. Herd factors studied were number of cows per year (mean number of cows during the previous $12 \mathrm{mo}$ ), milk production per cow and year (mean production during the previous $12 \mathrm{mo}$ ), herd SCC (geometric mean SCC during the previous $6 \mathrm{mo}$ ), incidence veterinary-treated cases of clinical mastitis (VTCM; number of registered cases during the previous 6 mo per herd/number of cows at risk per herd), proportion of different breeds in the herd (during the previous 12 mo), prevalence of digital dermatitis (registered and reported by professional hoof trimmers during the latest 6 mo before the visit), and bedding material used in the herd. As none of the continuous herd factors were linearly related to the outcome variable, they were all categorized using percentiles.

Information from the official milk recording scheme was also used to evaluate associations between cow factors and presence of UCD, as well as grade of UCD, on a cow level. The cow factors were DIM, parity, breed, milk production ( $\mathrm{kg}$ of milk), and SCC at the test milking $\pm 15 \mathrm{~d}$ from the visit, and having a registered case of VTCM within $\pm 30 \mathrm{~d}$ of the visit. The continuous explanatory variables were assessed if they were linearly related to the outcome; and if not, they were either categorized using percentiles as cut-offs or transformed using the natural logarithm, Box-Cox transformation, or fractional polynomial regression. Associations between UCD or grade of UCD and cow factors were analyzed using univariable and multivariable mixed logistic regression models with herd as random factor.

All statistical analyses were performed using Stata (release 11.2; StataCorp LP, College Station, TX). For the multivariable models, collinearity between the independent variables was assessed pair-wise by calculation of Spearman rank correlations. If there was proof of collinearity $(\mathrm{r} \leq 0.70)$, the variable with lowest $P$-value in the univariable analysis was selected. Herds or cows with missing data for a variable were not included when that variable was in the model. Moreover, in all the multivariable models, biologically plausible 2-way interactions between the main effects were tested.

The model fit of the multivariable analyses was tested using Hosmer-Lemeshow goodness-of-fit test, and by visual examination of diagnostic plots, according to Hosmer and Lemeshow (2000) and Dohoo et al. (2010). 


\section{Case-Control Study}

Six of the herds included in the prevalence study were visited a second time to perform a case-control study at the cow level. Inclusion criteria were that the herd had at least 10 cows with UCD in the prevalence study, and that the farmer was interested in participating.

At the farm visit, 10 cows with UCD were selected as cases and 10 cows without UCD were selected as controls. The case and control cows were matched on breed, parity, and month of lactation.

Cow Data. Each cow was investigated regarding udder conformation and signs of mange around the tail or on the escutcheon of the udder. The following udder traits were investigated: fore udder attachment (angle between fore udder and abdominal wall), udder support (depth of cleft between rear udder quarters), udder depth (distance between deepest part of the udder and the hock), udder balance (depth of the rear udder in relation to depth of the front udder), and front teat placement (assessment of front teat position by looking from the rear). The evaluation was made according to a modified version of the scoring system developed by the International Committee for Animal Recording (ICAR), which is used in the common Nordic breeding evaluation (Knowledge Center for Agriculture, 2012). In the modified version, a 3 -grade scale (1-3), corresponding to the classes $1-3,4-6$, and 7-9, respectively, of the original scale, was used to simplify the evaluation. Signs of mange (e.g., sparse growth of hair or hairless areas, hyperkeratosis, crusts, redness, or serum transudation) were evaluated visually as previously described (Warnick et al., 2002).

The cases of UCD were scored based on size and appearance. They were classified as mild or severe according to system used in the first study, and according to a 6 -grade scale $(0=$ no UCD, $1=$ small papulae/ pustulae, hyperkeratosis and/or serum transudation, 2 $=$ wounds and/or crusts with or without small papulae/pustulae, hyperkeratosis or serum transudation on an area smaller than $25 \mathrm{~cm}^{2}, 3=$ wounds and/or crusts with or without small papulae/pustulae, hyperkeratosis or serum transudation on an area larger than $25 \mathrm{~cm}^{2}, 4$ $=$ wounds with pus with or without crusts, small papulae/pustulae, hyperkeratosis or serum transudation on an area smaller than $25 \mathrm{~cm}^{2}, 5=$ wounds with pus with or without crusts, small papulae/pustulae, hyperkeratosis or serum transudation on an area larger than 25 $\mathrm{cm}^{2}$ ), which was a modified version of the method used by Hansen and Nissen (2010).

Statistics. Associations between UCD and udder conformation traits or signs of mange were evaluated using univariable and multivariable conditional logistic regression models. All statistical analyses were performed using Stata (release 11.2; StataCorp LP). The model fit of the multivariable analysis was tested by visual examination of diagnostic plots according to Hosmer and Lemeshow (2000).

\section{RESULTS}

\section{Prevalence and Risk Factors}

Descriptive Data. The mean annual herd size and milk production for the participating herds was 126.5 cows (range: 54.5 to 409.5 cows) and $10,265 \mathrm{~kg}$ of milk/ cow-year (range: 7,931 to 11,660 kg of milk/cow-year), respectively. The most common breeds in the participating herds were Swedish Holstein (SH), Swedish Red $(\mathbf{S R})$, and cross-breeds $(\mathrm{SH} \times \mathrm{SR})$. The proportion of SH and SR varied from 0 to $100 \%$, and on average, the herds contained $53 \%$ SH cows and $38 \%$ SR cows. In one herd, the majority of cows were Jersey cows. The geometric bulk milk SCC (during the previous 6 mo before the herd visit) was 272,000 cells $/ \mathrm{mL}$ (range: 153,000 to 482,000 cells $/ \mathrm{mL}$ ). The incidence of VTCM during the same period varied from 0 to $5.6 \%$ with a mean of $1.9 \%$. Only 15 herds had claw trimming results from the period from May to October 2012. Among those, the prevalence of digital dermatitis varied from 0 to $0.4 \%$ with a mean of $0.1 \%$.

A total of 1,083 cows were investigated. Complete information on parity (mean: 2.3, SD: 1.4), DIM (mean: 180 d, SD: $131 \mathrm{~d}$ ), breed (SH: $\mathrm{n}=611$, SR: $\mathrm{n}=353$, Jersey: $\mathrm{n}=28, \mathrm{SH} \times \mathrm{SR}: \mathrm{n}=74$, other cross-breeds: $\mathrm{n}$ $=7$ ), and registrations of disease data was available from 1,073 of the cows $\pm 30 \mathrm{~d}$ from the herd visit (mean VTCM incidence: 0.02 cases/cow, SD: 0.14 cases/cow). Among these 1,073 cows, 983 had a milk recording \pm 15 $\mathrm{d}$ from the herd visit (mean milk production: $27 \mathrm{~kg}$ of milk, SD: $8.5 \mathrm{~kg}$ of milk; median SCC: 81,000 cells $/ \mathrm{mL}$ of milk, $50 \%$ central range: 32,000 to 221,000 cells $/ \mathrm{mL}$ of milk).

Prevalence of $\boldsymbol{U C D}$. Udder cleft dermatitis was found in $18.4 \%$ ( $\mathrm{n}=199,95 \%$ CI: $16.1-20.8)$ of 1,083 cows studied. Most $(69 \% ; \mathrm{n}=138)$ of the affected cows had mild lesions, whereas $31 \%(\mathrm{n}=61)$ had severe lesions.

The prevalence of UCD within herds varied from 0 to $39 \%$, and the mean within-herd prevalence was $18.5 \%$ (95\% CI: 14.4-22.6; Figure 1). The proportion of mild and severe cases of UCD varied between herds, but in 22 of the herds all or most cases were mild.

Risk Factors at the Herd Level. Results from the univariable analyses are given in Table 1 . Herds with a high yearly milk production, a high proportion of SR cows, a mean SCC $<200,000$ cells $/ \mathrm{mL}$, or a prevalence of digital dermatitis of $<0.054$ had a higher prevalence 


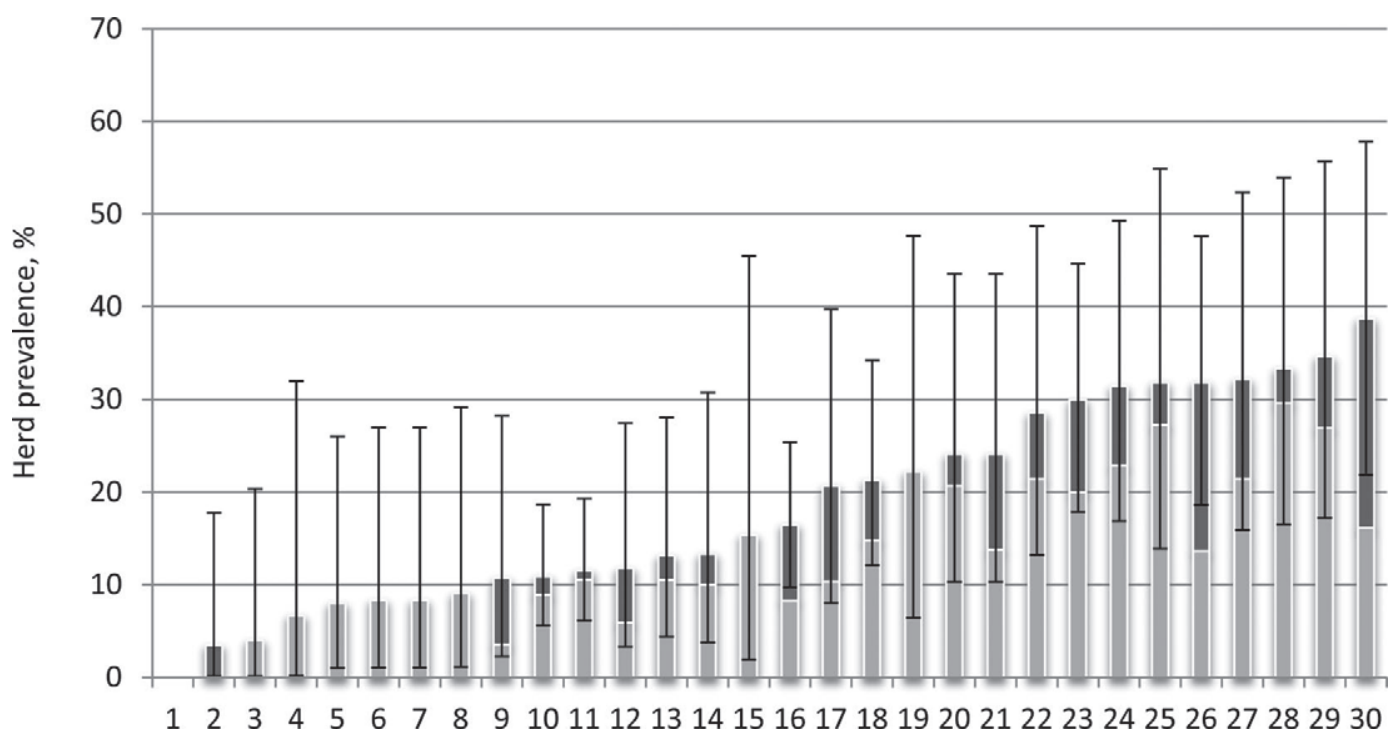

Figure 1. Herd prevalence (\%) and 95\% confidence interval of udder cleft dermatitis in 30 dairy herds in Östergötland, Sweden, sorted from the lowest to the highest prevalence. The proportion of mild (light gray) and severe (dark gray) cases within each herd is illustrated by different colors.

rate $(\mathbf{P R})$ of UCD than herds with lower milk production, a low proportion of SR cows, a SCC $\geq 200,000$ cells $/ \mathrm{mL}$, or a prevalence of digital dermatitis $\geq 0.054$.

In the final multivariable analysis (Table 2 ), only yearly milk production and proportion of SR cows remained significantly associated with UCD. The PR of UCD was 4.1 times higher in a herd with $\geq 50 \%$ SR and a yearly production $\geq 10,900 \mathrm{~kg}$ of milk/cow compared with a herd with $<20 \%$ SR and a yearly milk production of $<10,000 \mathrm{~kg}$ of milk/cow. No significant interactions were found. The variables included in the model explained approximately $16 \%$ of the variation of the data. Overdispersion was not observed for the model, the model showed reasonably good fit to the data, and no obvious patterns were seen in the residual plots.

Risk Factors at the Cow Level. The univariable analyses revealed significant associations between UCD and breed $(P<0.001)$, parity $(P<0.001)$, milk production $(P<0.001)$, and VTCM $(P<0.01)$, but not with DIM (tested both as categorical variable and as a transformed variable using fractional polynomial powers) or SCC. Swedish Red and cross-breeds had the highest proportion of UCD. The proportion of cows with UCD increased with increasing parity up to the third parity, but the proportion of severe UCD was higher in secondparity cows than in third-parity cows. Cows with mild UCD produced, on average, $1.5 \mathrm{~kg}$ more milk compared with cows without UCD, and cows with severe UCD produced, on average, $3.2 \mathrm{~kg}$ more than cows without UCD. The difference in milk production between cows with mild and severe UCD was not significant $(P=$
0.22). More cows with VTCM also had UCD compared with cows without VTCM $(P<0.01)$.

The results from the final multivariable analysis are given in Table 3. The herd effect was not significant; thus, ordinary logistic regression analysis was used instead of mixed logistic regression analysis. As the number of Jersey cows $(n=1)$, and cows of cross-breeds not including SH and SR $(\mathrm{n}=4)$, with milk production data $\pm 15 \mathrm{~d}$ from the herd visit was very low, these cows were excluded from the multivariable analysis. Moreover, cows with extreme DIM ( $>550 \mathrm{~d} ; \mathrm{n}=12)$ were also excluded (this was also done in the univariable analysis). Parity, breed, milk production $\pm 15 \mathrm{~d}$ from the herd visit, and VTCM $\pm 30 \mathrm{~d}$ from the herd visit were all associated with UCD in the multivariable analysis. The risk for UCD was higher in older cows (parity $\geq 3$ ) compared with first-parity cows, and we observed a tendency $(P<0.07)$ for cows in second parity to have a lower risk for UCD than older cows. Swedish Red cows had a higher risk for UCD than SH cows, and cross-breeds of SH and SR. The risk for UCD increased with increasing milk production, and the risk of UCD was approximately 3 times higher for cows that had been VTCM $\pm 30 \mathrm{~d}$ from the herd visit. No significant interactions were found between the main effects. The variables included in the model explained $10 \%$ of the variation of data. The model showed good fit to the data, and no obvious patterns were seen in the residual plots. A few outliers were observed but removing them did not improve the fit of the model.

Questionnaire. Among the 29 farmers questioned, 25 had previously observed UCD in the herd. Most the 
Table 1. Mean prevalence of udder cleft dermatitis (UCD) in 30 Swedish dairy herds depending on several risk factors at herd level, and results from the univariable Poisson regression analyses of associations between these factors and prevalence of UCD in the herds

\begin{tabular}{|c|c|c|c|}
\hline Risk factor $^{1}$ & $\begin{array}{l}\text { Mean \% } \\
\quad(\mathrm{SD})\end{array}$ & $\begin{array}{l}\text { No. of } \\
\text { herds }\end{array}$ & $P$-value \\
\hline \multicolumn{4}{|l|}{ Herd size, cow-years } \\
\hline$<90$ & $16.5(12.0)$ & 11 & \multirow{3}{*}{0.43} \\
\hline $90-109$ & $21.4(10.2)$ & 9 & \\
\hline$\geq 110$ & $18.2(10.0)$ & 10 & \\
\hline \multicolumn{4}{|c|}{ Milk production, $\mathrm{kg} /$ cow-year } \\
\hline$<10,000$ & $12.6(8.8)$ & 10 & \multirow[t]{3}{*}{0.017} \\
\hline $10,000-10,899$ & $16.8(10.7)$ & 10 & \\
\hline$\geq 10,900$ & $26.1(9.6)$ & 10 & \\
\hline \multicolumn{4}{|l|}{ Proportion of SH cows, $\%$} \\
\hline$<40$ & $24.0(11.0)$ & 10 & \multirow[t]{3}{*}{0.005} \\
\hline $40-69$ & $16.5(10.7)$ & 9 & \\
\hline$\geq 70$ & $15.2(10.7)$ & 11 & \\
\hline \multicolumn{4}{|l|}{ Proportion of SR cows, $\%$} \\
\hline$<20$ & $12.8(9.3)$ & 10 & \multirow{3}{*}{$<0.001$} \\
\hline $20-49$ & $18.4(10.7)$ & 11 & \\
\hline$\geq 50$ & $25.2(10.5)$ & 9 & \\
\hline \multicolumn{4}{|l|}{ Bedding material } \\
\hline Sawdust/wood shavings & $17.6(12.1)$ & 17 & \multirow[t]{3}{*}{$0.12^{2}$} \\
\hline Straw & $21.6(10.5)$ & 10 & \\
\hline Peat & $13.7(2.5)$ & 3 & \\
\hline \multicolumn{4}{|l|}{ SCC $, \times 1,000$ cells $/ \mathrm{mL}$} \\
\hline$<200$ & $27.5(11.1)$ & 6 & \multirow{3}{*}{0.014} \\
\hline $200-299$ & $16.7(10.6)$ & 14 & \\
\hline$\geq 300$ & $15.7(9.6)$ & 10 & \\
\hline \multicolumn{4}{|l|}{ Incidence VTCM, \% } \\
\hline$<1$ & $16.1(11.4)$ & 14 & \multirow[t]{2}{*}{0.61} \\
\hline$\geq 1$ & $20.6(10.6)$ & 16 & \\
\hline \multicolumn{4}{|c|}{ Prevalence digital dermatitis, $\%$} \\
\hline$<0.054$ & $25.3(11.4)$ & 8 & \multirow[t]{2}{*}{0.040} \\
\hline$\geq 0.054$ & $18.9(10.3)$ & 7 & \\
\hline
\end{tabular}

${ }^{1} \mathrm{SH}=$ Swedish Holstein; SR = Swedish Red; VTCM = veterinary-treated clinical mastitis.

${ }^{2}$ Peat was not included in the model.

farmers did not think that UCD was common, but 7 considered UCD to be an important health problem. The reasons given for UDC being an important health problem were that UCD causes pain, has no efficient treatment, causes a bad smell, and may be associated with mastitis. Treatments tested by the farmers included application of teat spray, washing with water, application of antibacterial ointments, systemic or local administration of benzyl penicillin, systemic treatment with eprinomectin, and local treatment with oxytetracycline spray. Most farmers indicated that treatment had no effect or a slightly positive effect.

\section{The Case-Control Study}

The herds visited a second time had a UCD prevalence between 21 and $39 \%$. In this study, a total of 116 cows were investigated (60 case cows and 56 control

Table 2. Final multivariable Poisson regression analysis of herd risk factors associated with herd prevalence of udder cleft dermatitis in 30 Swedish dairy herds (pseudo $\mathrm{R}^{2}=0.16$ )

\begin{tabular}{lccccc}
\hline Variable & $\beta^{1}$ & $\mathrm{SE}(\beta)$ & $\mathrm{PR}^{2}$ & $95 \% \mathrm{CI}$ & $P$-value \\
\hline Intercept & -2.43 & 0.21 & - & - & - \\
Milk production, $\mathrm{kg} /$ cow-year & Ref. $^{3}$ & - & - & & - \\
$\quad<10,000$ & 0.24 & 0.21 & 1.27 & $0.84 ; 1.91$ & 0.25 \\
$\quad \begin{array}{l}10,000-10,899 \\
\geq 10,900\end{array}$ & 0.59 & 0.19 & 1.80 & $1.23 ; 2.63$ & 0.003 \\
Proportion Swedish Red, $\%$ & Ref. & - & - & - & - \\
$\quad<20$ & 0.40 & 0.19 & 1.50 & $1.03 ; 2.17$ & 0.03 \\
$20-49$ & 0.82 & 0.19 & 2.28 & $1.55 ; 3.33$ & $<0.001$ \\
$\geq 50$ & & & & & \\
\hline
\end{tabular}

${ }_{1} \beta=$ regression coefficient.

${ }^{2} \mathrm{PR}=$ prevalence rate.

${ }^{3}$ Reference category. 
Table 3. Final multivariable logistic regression analysis of cow factors associated with udder cleft dermatitis in 966 Swedish dairy cows (pseudo $\mathrm{R}^{2}=0.10$ )

\begin{tabular}{|c|c|c|c|c|c|}
\hline Variable & $\beta^{1}$ & $\operatorname{SE}(\beta)$ & $\begin{array}{l}\text { Odds ratio } \\
\quad(\mathrm{OR})\end{array}$ & $\begin{array}{c}95 \% \mathrm{CI} \\
\text { (OR) }\end{array}$ & $P$-value \\
\hline Intercept & -2.71 & 0.21 & - & - & - \\
\hline \multicolumn{6}{|l|}{ Parity } \\
\hline $1(\mathrm{n}=357)$ & Ref. $^{2}$ & - & - & - & - \\
\hline $2(\mathrm{n}=278)$ & 0.48 & 0.25 & 1.61 & $0.99 ; 2.63$ & 0.06 \\
\hline $3(\mathrm{n}=166)$ & 0.96 & 0.27 & 2.60 & $1.54 ; 4.41$ & $<0.001$ \\
\hline$\geq 4(\mathrm{n}=165)$ & 0.93 & 0.26 & 2.54 & $1.51 ; 4.27$ & $<0.001$ \\
\hline \multicolumn{6}{|l|}{ Breed $^{3}$} \\
\hline $\mathrm{SH}(\mathrm{n}=570)$ & Ref. & - & - & - & - \\
\hline $\mathrm{SR}(\mathrm{n}=327)$ & 1.26 & 0.19 & 3.54 & $2.45 ; 5.12$ & $<0.001$ \\
\hline $\mathrm{SH} \times \mathrm{SR}(\mathrm{n}=69)$ & 0.34 & 0.39 & 1.41 & $0.66 ; 3.03$ & 0.38 \\
\hline Milk yield, $\mathrm{kg} / \mathrm{d}(\mathrm{n}=966)$ & 0.03 & 0.01 & 1.03 & $1.01 ; 1.05$ & 0.003 \\
\hline \multicolumn{6}{|l|}{ Mastitis $( \pm 30 \mathrm{~d})$} \\
\hline No $(\mathrm{n}=948)$ & Ref. & - & - & - & - \\
\hline Yes $(\mathrm{n}=18)$ & 1.20 & 0.52 & 3.33 & $1.20 ; 9.29$ & 0.02 \\
\hline
\end{tabular}

cows). Among cows with UCD, 15, 28, 3, 32, and $22 \%$ had scores 1, 2, 3, 4, and 5, respectively. All UCD cases scored 4 and 5 were classified as severe, and all cases scored 1 were classified as mild. Among 17 cases with a score of 2,14 were classified as mild and 3 as severe. Two cases had a score of 3 , and 1 each was classified as mild or severe. In total, $44 \%$ of UCD cases were considered mild and $64 \%$ severe. In one herd, which had the highest UCD prevalence at the first visit, only 6 suitable control cows were found. In the univariable and multivariable analyses, only cows in a matching case-control pair were included $(\mathrm{n}=112$ cows $)$.

Because the number of cows was small $(\mathrm{n}=112)$, associations between udder conformation and UCD were only evaluated based on presence or absence of UCD, not based on the actual scores. The results of the univariable analyses are given in Table 4. Udder cleft dermatitis was less common in cows with a strong fore udder attachment (score 3) compared with cows with a loose attachment. Cows with an indentation or a fold in the anterior junction between the udder and the abdominal wall tended to have a higher prevalence of UCD. Signs of mange were found in only 2 of the herds and had no association with UCD.

In the multivariable analysis, the only significant factor was anterior udder attachment (Table 5). A strong attachment was associated with a low risk of UCD.

\section{DISCUSSION}

\section{Prevalence of UCD}

The prevalence of UCD among dairy cows and dairy herds was higher than anticipated, and prevalence varied markedly between herds. Only one of the herds had no cases of UCD, whereas 11 herds had a herd prevalence above $22 \%$, which was the highest prevalence reported in previous studies (Beattie and Taylor, 2000). None of the 20 Dutch herds in the study by Amersfort et al. (2012) had prevalence above 13\%. The high prevalence in the present study can, to a certain degree, be explained by the criteria used when diagnosing UCD; more severe skin lesions were needed for a UCD diagnosis in the study by Amersfort et al. (2012). Moreover, $33 \%$ of the cows participating in the present study were SR cows, which had a greater risk for UCD than $\mathrm{SH}$ cows. It is difficult to compare the prevalence of UCD with other studies as only one or a few herds were included in those studies, and the herds were not randomly selected. In addition, only 2 studies (Hansen and Nissen, 2010; Amersfort et al., 2012) clearly define which type of lesions they classified as UCD.

Most cases of UCD were considered mild, but the within-herd proportion of mild and severe cases varied markedly. The higher proportion of mild cases could be because both UCD in early phase and in the healing phase are likely scored as mild. It is also possible that not all UCD cases become severe.

\section{Risk Factors for UCD}

Breed and milk production were identified as risk factors at both the herd and cow levels. The prevalence of UCD was highest in herds with a high proportion of SR cows and in SR cows, and highest in high-producing herds and cows.

To our knowledge, breed has not previously been identified as a risk factor for UCD, possibly because 
Table 4. Number $(\%)$ of cows with $(n=56)$ or without $(n=56)$ udder cleft dermatitis (UCD) depending on udder conformation traits and presence of mange, and results from the univariable conditional logistic regression analyses of associations between these variables and UCD

\begin{tabular}{|c|c|c|c|}
\hline Variable & Without UCD & With UCD & $P$-value \\
\hline \multicolumn{4}{|c|}{ Anterior udder attachment } \\
\hline 1 (loose) & $14(25)$ & $12(21)$ & \multirow[t]{3}{*}{0.02} \\
\hline 2 (intermediate) & $26(46)$ & $39(70)$ & \\
\hline 3 (strong) & $16(29)$ & $5(9)$ & \\
\hline \multicolumn{4}{|l|}{ Udder ligament } \\
\hline 1 (weak) & $9(16)$ & $6(11)$ & \multirow[t]{3}{*}{0.38} \\
\hline 2 (intermediate) & $26(46)$ & $23(41)$ & \\
\hline 3 (strong) & $21(38)$ & $27(48)$ & \\
\hline \multicolumn{4}{|l|}{ Udder depth } \\
\hline 1 (deep) & $5(9)$ & $6(11)$ & \multirow[t]{3}{*}{0.49} \\
\hline 2 (intermediate) & $31(55)$ & $34(61)$ & \\
\hline 3 (high) & $20(36)$ & $16(29)$ & \\
\hline \multicolumn{4}{|l|}{ Udder balance } \\
\hline 1 (deep rear udder) & $10(18)$ & $10(18)$ & \multirow[t]{3}{*}{0.125} \\
\hline 2 (same level) & $46(82)$ & $43(77)$ & \\
\hline 3 (deep front udder) & $0(0)$ & $3(5)$ & \\
\hline \multicolumn{4}{|c|}{ Front teat placement (rear view) } \\
\hline 1 (wide) & $8(14)$ & $7(13)$ & \multirow{3}{*}{0.95} \\
\hline 2 (intermediate) & $47(84)$ & $48(86)$ & \\
\hline 3 (close) & $1(2)$ & $1(2)$ & \\
\hline \multicolumn{4}{|c|}{ Presence of indentation or fold } \\
\hline No & $34(61)$ & $24(43)$ & \multirow[t]{2}{*}{0.065} \\
\hline Yes & $22(39)$ & $32(57)$ & \\
\hline \multicolumn{4}{|l|}{ Signs of mange } \\
\hline No & $45(80)$ & $45(82)$ & \multirow[t]{2}{*}{1.00} \\
\hline Yes & $11(20)$ & $11(18)$ & \\
\hline
\end{tabular}

mainly Holstein cows were included in previous studies. In combination with the association found between UCD and VTCM, the higher risk in SR cows is remarkable because SR cows has better udder health than $\mathrm{SH}$ cows at the national level (Persson Waller et al., 2009). In the breeding evaluation, however, SH cows have slightly better udder conformation than SR cows (Swedish Dairy Association, 2005). According to the breeding evaluation, the greatest difference between breeds is observed in udder depth, which is deeper in SR cows.

No other study has been able to show any association between UCD and milk production (Warnick et al., 2002; Hansen and Nissen, 2010), but Amersfort et al. (2012) found a tendency for production level to be connected with UCD. We can hypothesize that production level is associated with udder conformation, internal milk pressure, udder edema, or local immune defense mechanisms.

In the present study, we found an increased risk of UCD in third-parity or older cows, which is in line with previous studies (Beattie and Taylor, 2000; Warnick et al., 2002; Hansen and Nissen, 2010). The increased risk may be explained by the fact that the shape of the udder changes as cows get older (Hansen and Nissen, 2010). Other factors that may be important are that older cows have more days at risk, or that the lesions may easily return when they have once affected the udder. The only cow factor in which the difference between cows with mild and severe UCD was significant was parity (data not shown). The risk for mild UCD was greater in third-parity cows than in second-parity

Table 5. Results from the final multivariable conditional logistic regression analysis of udder conformation traits associated with udder cleft dermatitis in 112 Swedish dairy cows (pseudo $\mathrm{R}^{2}=0.10$ )

\begin{tabular}{lccccc}
\hline Variable & & & Odds ratio & $95 \%$ CI & \\
$($ OR $)$ & & $P$-value \\
\hline Anterior udder attachment & $\beta^{1}$ & $\mathrm{SE}(\beta)$ & & & - \\
Score 2 & Ref. $^{2}$ & - & - & - & - \\
Score 1 & -0.51 & 0.53 & 0.60 & $0.21 ; 1.70$ & 0.33 \\
Score 3 & -1.41 & 0.57 & 0.24 & $0.08 ; 0.75$ & 0.01 \\
\hline
\end{tabular}

${ }^{1} \beta=$ regression coefficient.

${ }^{2}$ Reference category. 
cows, whereas the risk for severe UCD was greater in second-parity cows than in older cows. The reasons for these findings are not known.

Days in milk had no significant association with UCD in the present study. In previous studies, Hansen and Nissen (2010) found a tendency for increased risk for UCD in relation to increased DIM, and Warnick et al. (2002) found an association between DIM and UCD in first-parity cows.

A link between UCD and digital dermatitis has been suggested (Boyer and Singleton, 1998; Stamm et al., 2009) but, in line with Hansen and Nissen (2010), we found no such indication. The prevalence of digital dermatitis was, however, very low in the studied herds, indicating that those cases may not be of the contagious type. It should be noted, however, that the low prevalence could be due to under-reporting. Infections with Treponema spp. are evaluated as a causative factor in severe cases of shoulder lesions and ear necrosis in pigs (Pringle et al., 2009; Pringle and Fellström, 2010). The similarities between such lesions and UCD might indicate a possible role of Treponema spp. or other bacteria in severe cases of UCD. In the case-control study, spirochetes were found in samples from severe cases of UCD, using microscopy, but only in 4 of 6 herds (data not shown). The fact that the highest numbers of spirochetes were found in samples from the herd with the highest prevalence of UCD (and that this herd also had a high prevalence of severe UCD) indicates the need for more studies on associations between UCD and digital dermatitis.

In the case-control study, udder conformation and mange were investigated as potential risk factors for UCD. A strong fore udder attachment was associated with a lower prevalence of UCD, which is in line with studies by Hansen and Nissen (2010) and Amersfort et al. (2012). None of the other traits had a significant association with UCD, but presence of an indentation, or a fold, in the anterior junction between the udder and the abdominal wall tended to be associated with UCD in the univariable analysis. A strong udder support (Beattie and Taylor, 2000; Hansen and Nissen, 2010) and deep udder depth (Hansen and Nissen, 2010; Amersfort et al., 2012) have, however, been associated with more UCD in other studies. The differences between studies may, at least partly, be due to differences in study design and the number of cows included. Moreover, evaluation of udder conformation is subjective and the results could have been different with another evaluator. Some of the present breeding goals for udder conformation are strong fore udder attachment and intermediate udder depth (Nordic Cattle Genetic Evaluation, 2013), which should lead to fewer cases of UCD. However, other aims are strong udder support and high production, which could have opposite effects, according to results from this and other studies.

Mange was not associated with UCD in the present study, which together with results from other studies (Hansen and Nissen, 2010; Warnick et al., 2002) indicates that mange does not play a major role in UCD.

\section{Associations Between UCD and Mastitis}

In this study, cows with UCD had 3.3 times greater risk for VTCM $\pm 30 \mathrm{~d}$ from the diagnosis of UCD compared with cows without UCD. To our knowledge, this is the first study identifying an association between UCD and mastitis. Few studies on UCD and mastitis have been performed, but Warnick et al. (2002) did not find any significant association. In that study, however, only one herd was included and the type of mastitis was not specified. Based on our findings, it is not possible to say if mastitis is a risk factor for UCD or vice versa, but the latter is most likely. Capurro et al. (2010) showed that skin lesions, and especially hock lesions, can be an important reservoir for the udder pathogen Staphylococcus aureus. It is also likely that UCD would be a favorable environment for udder pathogens, and the proximity to the teats makes a risk for spread of bacteria from the UCD to the udder likely. We found no significant association, however, between UCD and SCC, indicating that UCD does not result in an increased risk for subclinical mastitis.

\section{Final Remarks}

In this study, only one county of Sweden was included, and it is not known if the results reflect the situation in herds with freestalls and milking parlor in other parts of the country. The mean yearly milk production was, however, $800 \mathrm{~kg}$ higher than the national average for such herds (N.-E. Larsson, Swedish Dairy Association, Stockholm, Sweden, personal communication), which could indicate a marginally lower prevalence in similar herds in the rest of the country. Breed is another factor that can differ between regions of Sweden. The prevalence of UCD might be lower in regions where SH cows predominate. Whether the UCD prevalence is different in automatic milking system herds or in herds with tiestalls is not known.

The variables in the herd and cow models only explained 16 and $10 \%$, respectively, of the variation in the UCD data, indicating that other important causative factors are yet to be found. The effect of herd was not significant as a random factor in the multivariable cow model, indicating that most of the variation in the presence of UCD is explained by cow factors and is not due to, for example, management factors. However, as the 
30 herds that were included in this study all had similar housing and milking systems, management differences were probably not great. If more herds and herds with other housing and milking systems had been included, the herd effect might have been significant.

An important weakness of this and other studies is that it was not possible to investigate risk factors important in the initiation and recovery of UCD. For this, longitudinal studies are needed. Such studies would also make it easier to evaluate a possible link between UCD and other diseases. The role of microorganisms in the development of UCD needs further study in a large number of herds. In addition, the importance of other risk factors, such as hygiene, BCS, and aspects of udder anatomy that affect blood circulation in the anterior part of the udder, should be studied. Studies addressing these issues have been initiated.

\section{CONCLUSIONS}

Udder cleft dermatitis was common in dairy cows in herds with freestalls and milking parlor in the county of Östergötland, and the herd prevalence of UCD varied markedly. Risk factors for UCD on the herd and cow levels were milk yield and breed. Parity and incidence of VTCM was also found to be risk factors for UCD on the cow level. Moreover, the risk for UCD was lower in cows with a strong anterior udder attachment. The models explained only a small part of the variation in data. As the condition is common and most likely has a negative effect on an animal welfare, more research on factors of importance for prevention of UCD is needed.

\section{REFERENCES}

Allenstein, L. C. 1991. Mites cause many of the smelly udder sores. Hoard's Dairyman 136:507.

Amersfort, K., R. G. M. O. van Riekerink, O. C. Sampimon, G. Hooijer, and T. J. G. M. Lam. 2012. Prevalence and risk factors of udder cleft dermatitis in Dutch dairy herds. Pages 211-212 in Proc. National Mastitis Council 51st Annu. Mtg., St. Pete Beach, FL. Natl. Mastitis Counc., Madison, WI.
Beattie, K. G., and D. J. Taylor. 2000. An investigation into intertrigo (necrotic dermatitis or "foul udder") in dairy cows. Cattle Pract. 8:377-380

Boyer, P., and G. Singleton. 1998. Digital dermatitis, superfoul and severe necrotic dermatitis [correction of enteritis] of the udder in dairy cows. Vet. Rec. 142:147-148.

Capurro, A., A. Aspán, H. Ericsson Unnerstad, K. Persson Waller, and K. Artursson. 2010. Identification of potential sources of Staphylococcus aureus in herds with mastitis problems. J. Dairy Sci. 93:180-191.

Dohoo, I., W. Martin, and H. Stryhn. 2010. Veterinary Epidemiologic Research. 2nd ed. VER Inc., Charlottestown, PEI, Canada.

Evans, N. J., D. Timofte, S. D. Carter, J. M. Brown, R. Scholey, D. H. Read, and R. W. Blowey. 2010. Association of treponemes with bovine ulcerative mammary dermatitis. Vet. Rec. 166:532-533.

Hansen, M. J., and M. M. Nissen. 2010. A Clinical Study of Udder Cleft Dermatitis on a Danish Dairy Farm. Det Biovidenskabelige Fakultet for Fødevarer, Veterinærmedicin og Naturressourcer, Institut for Produktionsdyr og Heste, Copenhagen University, Copenhagen, Denmark.

Hosmer, D. W., and S. Lemeshow. 2000. Applied Logistic Regression. John Wiley \& Sons Inc., New York, NY.

Knowledge Center for Agriculture. 2012. Assessing linear conformation traits, drawingsand descriptions. Accessed Nov. 5, 2012.https://www. landbrugsinfo.dk/Kvaeg/Avl/Kaaring-og-eksterioertal/Filer/kar_ tekst_incl_tegn_mlkeng.pdf.

Nordic Cattle Genetic Evaluation. 2013. NAV routine genetic evaluation of dairy cattle - Data and genetic models. Accessed Aug. 21, 2013. http://www.nordicebv.info/NR/rdonlyres/5CD2E4DCF82A-4809-A770-3022E270E205/0/PrinciplesNyeste.pdf.

Persson Waller, K. 2003. Nekrotisk dermatit framtill på juvret hos mjölkkor. Svensk Veterinärtidning 55:11-16. (Swedish with English summary).

Persson Waller, K., B. Bengtsson, A. Lindberg, A. Nyman, and H. Ericsson Unnerstad. 2009. Incidence of mastitis and bacterial findings at clinical mastitis in Swedish primiparous cows - Influence of breed and stage of lactation. Vet. Microbiol. 134:89-94.

Pringle, M., A. Backhans, F. Otman, M. Sjölund, and C. Fellström. 2009. Isolation of spirochetes of genus Treponema from pigs with ear necrosis. Vet. Microbiol. 139:279-283.

Pringle, M., and C. Fellström. 2010. Treponema pedis isolated from a sow shoulder ulcer. Vet. Microbiol. 142:461-463.

Stamm, L. V., R. L. Walker, and D. H. Read. 2009. Genetic diversity of bovine ulcerative mammary dermatitis-associated Treponema. Vet. Microbiol. 136:192-196.

Swedish Dairy Association. 2005. Avelsvärden för bruksegenskaper Gemensam Nordisk Avelsvärdering (NAV). Accessed Dec. 10, 2012 http://svenskmjolk.se/Global/Dokument/EPi-tr\%C3\%A4det/Mj \%C3\%B6lkg\%C3\%A5rden/Avel/Avelsv\%C3\%A4rden\%20f\%C3\% B6r\%20bruksegenskaper\%20NAV.pdf.

Warnick, L. D., D. Nydam, A. Maciel, C. L. Guard, and S. E. Wade. 2002. Udder cleft dermatitis and sarcoptic mange in a dairy herd. J. Am. Vet. Med. Assoc. 221:273-276. 